\title{
Transport and storage of spermatozoa in the female reproductive tract of the brown marsupial mouse, Antechinus stuartii (Dasyuridae)
}

\author{
D. A. Taggart and P. D. Temple-Smith \\ Department of Anatomy, Monash University, Clayton, Victoria 3168, Australia
}

\begin{abstract}
Summary. Female brown marsupial mice were mated and changes in the number and distribution of spermatozoa were assessed in several regions of the reproductive tract at $1,2,3,7,10,14$ and 18 days after mating. Approximately $40 \times 10^{3}$ spermatozoa/side were present in the female reproductive tract between Days 1 and 7 after a single mating. This had decreased (to $\sim 9 \times 10^{3}$ spermatozoa/side) by Days 10 and 14 after mating; by Day 18 no spermatozoa were recovered. The maximum number of spermatozoa recorded in a female tract was $\sim 72 \times 10^{3}$ spermatozoa/side (Day 5 female, death in laboratory) and the minimum recorded was $\sim 2 \times 10^{3}$ spermatozoa/side on Day 2 after mating.

Between Days 1 and 7 after mating most spermatozoa were located in the uterus and lower isthmus (isthmus 1) and spermatozoa were rarely found in the lateral vaginae. By $24 \mathrm{~h}$ after mating most spermatozoa $(\sim 60 \%)$ were found in isthmus 1 , but $\sim 35 \%$ were still present in the uterus. Histological observations of the lower isthmus at this time showed that large numbers of spermatozoa were present in both the lumen of the duct and the sperm storage crypts which are located in this region. By Day 7 after mating $\sim 91 \%$ of all spermatozoa in the female tract were in isthmus 1 , most of these being confined to the sperm storage crypts. On Days 10 and 14 after mating almost all spermatozoa in the tract were in the crypt regions of isthmus 1 and on Day 18 degenerating spermatozoa were observed. No special orientation or association of spermatozoa in relation to crypt cells was observed.
\end{abstract}

These results show that, although the number of spermatozoa inseminated is low by mammalian standards sperm transport in this species is extremely efficient and a large proportion of spermatozoa reaches the isthmus before ovulation ( $\sim 1$ in 1 to 1 in 7 ). Several observations may explain the remarkable success of these low numbers of spermatozoa, including specializations of the reproductive tract which may have a directing effect on sperm movement and the special relationship which exists between spermatozoa and the oviducal environment which results in viable sperm storage. Recent observations suggest that an unusual sinusoidal mode of progressive motility observed in this species, may also influence the success of the low numbers of ejaculated spermatozoa.

Keywords: marsupial; spermatozoa; sperm storage; oviduct; isthmus; ultrastructure

\section{Introduction}

Most marsupials and eutherian mammals inseminate many more spermatozoa than are required for fertilization, but, despite this, few spermatozoa survive to participate in this process (Overstreet \& Cooper, 1978, 1979; Bedford et al., 1984). Several factors are thought to influence the numbers of spermatozoa ejaculated, not the least of which is the selection process spermatozoa face in the female tract (Bedford et al., 1984). Successful transport of viable spermatozoa through the female 
reproductive tract to the site of fertilization is an essential prerequisite for reproduction and in most mammals large numbers of spermatozoa need to be inseminated to achieve this. Exceptions are found in representatives of several marsupial families, such as the opossums (Didelphidae) and the carnivorous Australian dasyurid marsupials in which extraordinarily low numbers of spermatozoa have been found in the epididymis and the ejaculate (Bedford et al., 1984; Breed et al., 1989; Taggart \& Temple-Smith, 1989, 1990a). Bedford et al. (1984) suggested that, in species in which a mechanism exists to protect the acrosome and/or the whole spermatozoon from degenerative changes in the female tract, such as oviducal crypt storage of spermatozoa or $-\mathrm{S}-\mathrm{S}-$ crosslinking of acrosomal proteins, a much lower rate of sperm production can be maintained without compromising fertility.

In the brown marsupial mouse (Antechinus stuartii) the drive to reproduce is complicated further by total spermatogenic failure before the breeding season (Kerr \& Hedger, 1983), continuous spermatorrhoea, which drains the sperm reserves even in unmated males (Taggart \& TempleSmith, 1990a), a limited capacity for caudal storage of mature spermatozoa in the epididymis (Taggart \& Temple-Smith, 1989, 1990a) and, in the wild, the death of the entire male population within 2 or 3 weeks of mating (Lee et al., 1977; Bradley et al., 1980; Lee \& Cockburn, 1985), often before females have ovulated (Selwood \& McCallum, 1987). As if to offset these negative aspects of reproduction, dasyurid marsupials, including $A$. stuartii, have evolved specialized crypts in the isthmus of the oviduct (Hill \& O'Donoghue, 1913; Woolley, 1966; Godfrey, 1969; Selwood, 1983, 1987), which are able to store spermatozoa in a viable state until required for fertilization up to 2 weeks later. Spermatozoa of this species have been shown to have an unusual, but effective, sinusoidal mode of progressive motility (Taggart \& Temple-Smith, 1990b) which may explain the highly efficient transport of ejaculated spermatozoa to the oviducal storage crypts in this species and probably other dasyurids (Breed et al., 1989).

In this study we determined the number and distribution of spermatozoa after mating in the reproductive tract of female brown marsupial mice and compared our data with previous results on sperm content of the epididymis during the breeding season and the estimated sperm content of the ejaculate at mating (Taggart \& Temple-Smith, 1990a). From these studies we have quantitated the efficiency of sperm transport and the duration of sperm storage in female brown marsupial mice and examined the ultrastructural characteristics of the oviducal sperm storage crypts in $A$. stuartii for comparison with information on another dasyurid species, Sminthopsis crassicaudata, the fat-tailed dunnart (Breed et al., 1989).

\section{Materials and Methods}

\section{Animal capture and maintenance}

The 10 male and 21 female brown marsupial mice required for this study were trapped in Australia during July 1989 in wet sclerophyll forest near Powelltown, 60 miles east of Melbourne, Victoria (Permit no. 88/120, issued by the Victorian Department of Conservation, Forests and Lands). After capture, animals were transferred to the laboratory, housed in individual cages and maintained as described by Taggart \& Temple-Smith (1990a) for several days until required for experimentation.

\section{Mating trials}

Oestrus was determined by the presence of cornified epithelial cells in urine samples (Godfrey 1969; Selwood 1985) collected 3 times a week during July and early August. Each male was placed with an oestrous female and allowed to mate once. Animals were monitored throughout mating and urine samples were collected at the conclusion of mating. A successful mating was not recorded unless spermatozoa were present in female urine samples.

\section{Animal groups}

Females were divided into 7 groups of 3 animals and killed $1,2,3,7,10,14$ or 18 days after mating. 


\section{Tissue preparation}

Females were killed with an intraperitoneal injection of pentobarbitone sodium $(0.2 \mathrm{ml}, 60 \mathrm{mg} / \mathrm{kg}$; Nembutal: Abbott Laboratories, Asquith, NSW, Australia) and the reproductive tract was removed, gently dissected free of connective tissue (especially around the oviduct) and placed in Dulbecco's modified Eagle's medium (DMEM: Gibco Pty Ltd, Canada L7P 1A1). On each side, the lateral vagina, uterus, isthmic regions 1 and 2, and ampulla (Fig. 1) were rapidly isolated using 6/0 nylon sutures (Ethnor Pty Ltd, Sydney, Australia) to prevent movement of spermatozoa between regions (Fig. 1). Junctions between isthmic regions 1 and 2 and the ampulla were identified under a dissecting microscope by changes in the thickness of the wall of the duct and in duct diameter. Each side of the reproductive tract was then isolated: one was pinned out on modelling wax and fixed by immersion in a glutaraldehyde-based fixative in $0.1 \mathrm{M}$ cacodylate buffer (Taggart \& Temple-Smith, 1990a) for structural studies and the other was used to examine sperm distribution in each region.

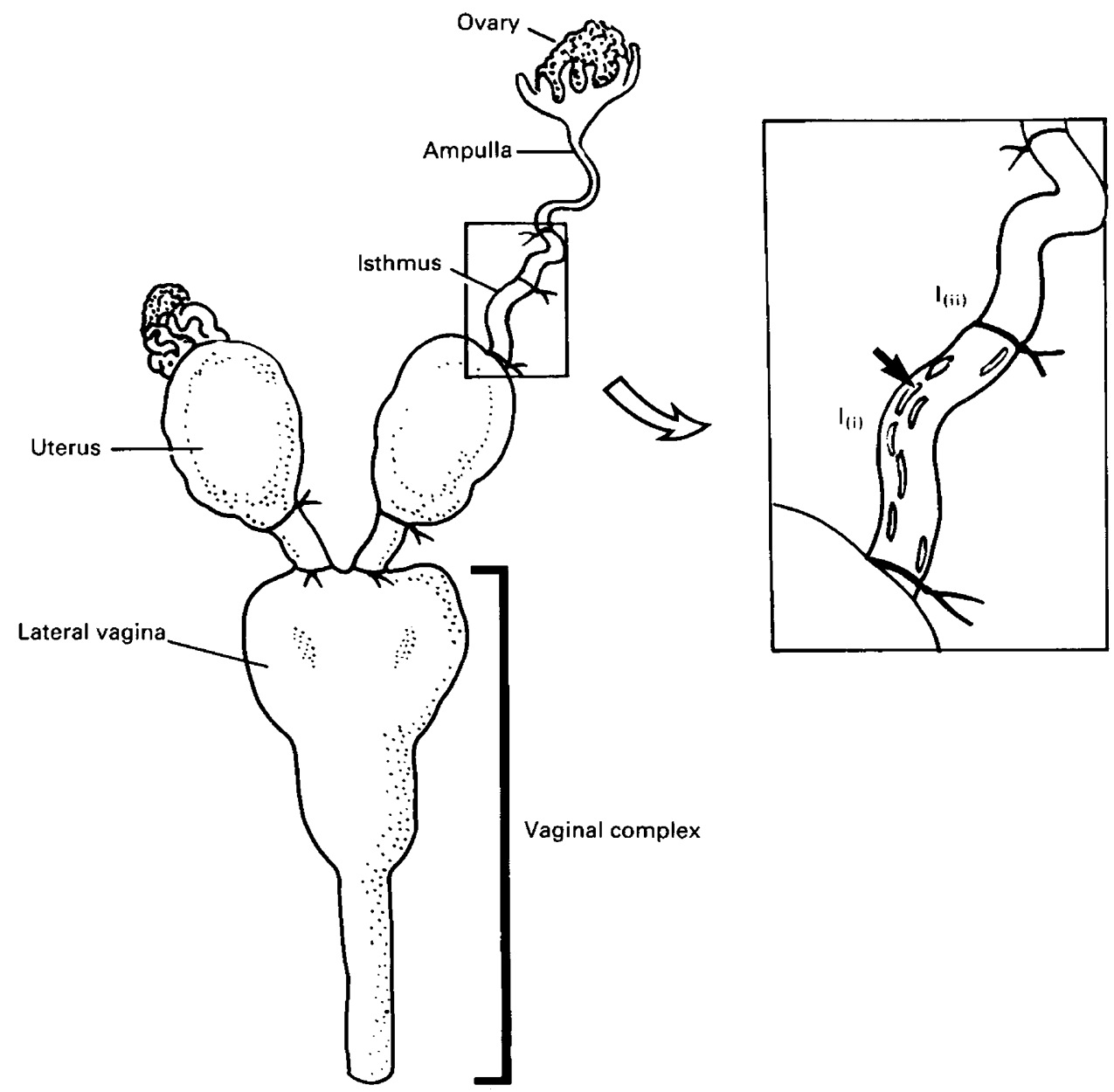

Fig. 1. Female reproductive tract of a brown marsupial mouse. Note placement of sutures and division of the isthmus into 2 regions. Arrow indicates regions containing large accumulations of spermatozoa; $\times 3$.

\section{Light and electron microscopy}

For light (LM) and transmission electron microscopy (TEM) the fixed tissues were divided into lateral vagina, uterus (body), uterus (neck), isthmic regions 1 and 2, ampulla and ovary and processed routinely for TEM (Taggart 
$\&$ Temple-Smith, 1989). Sections of $1 \mu \mathrm{m}$ from each region were stained in toluidine blue and examined with a Leitz Orthoplan microscope, but only the uterus and isthmic region 1 are described further here. For TEM, silver-grey thin sections were stained in aqueous uranyl acetate and lead citrate and examined in a Jeol 100B electron microscope.

\section{Estimation of number of spermatozoa}

Marsupial spermatozoa are more fragile than their eutherian counterparts (Temple-Smith \& Bedford, 1976; Cummins, 1981) and therefore more prone to disintegrate if given harsh chemical or mechanical treatments. Because of this we used the more gentle, but thorough, manual sperm extraction procedures described below rather than standard homogenization methods (Amann et al., 1976) to separate spermatozoa from reproductive tract segments.

Oviducal tissues. After division of the oviduct into isthmus 1 and 2 and ampulla (Fig. 1), spermatozoa were forced into the surrounding medium by squeezing and stripping along the length of each segment with blunt-nosed forceps. This procedure appeared to remove most of the spermatozoa and epithelial cells in the first squeeze, but the medium was then replaced and the procedure repeated until no further spermatozoa could be obtained. Six drops of homogenizing fluid (Taggart \& Temple-Smith, 1990a) were added to medium containing spermatozoa to prevent agglutination of spermatozoa and epithelial cells. This mixture was diluted to a known volume with DMEM and the total number of spermatozoa calculated using a Bright-Line haemocytometer (Reichert Scientific Instruments, Warner-Lambert Technologies Inc., New York, NY, USA).

After sperm extraction, tissue was fixed in Bouin's fluid processed for routine LM, stained and examined for the presence of spermatozoa to ensure that the procedure had been successful.

Lateral vagina and uterus. These regions were placed in several drops of DMEM, luminal surfaces were exposed by longitudinal incision (e.g. uterus, Fig. 2) and spermatozoa removed by firmly scraping the exposed inner surfaces with blunt-nosed forceps. Spermatozoa and tissues were then prepared and assessed as described above.
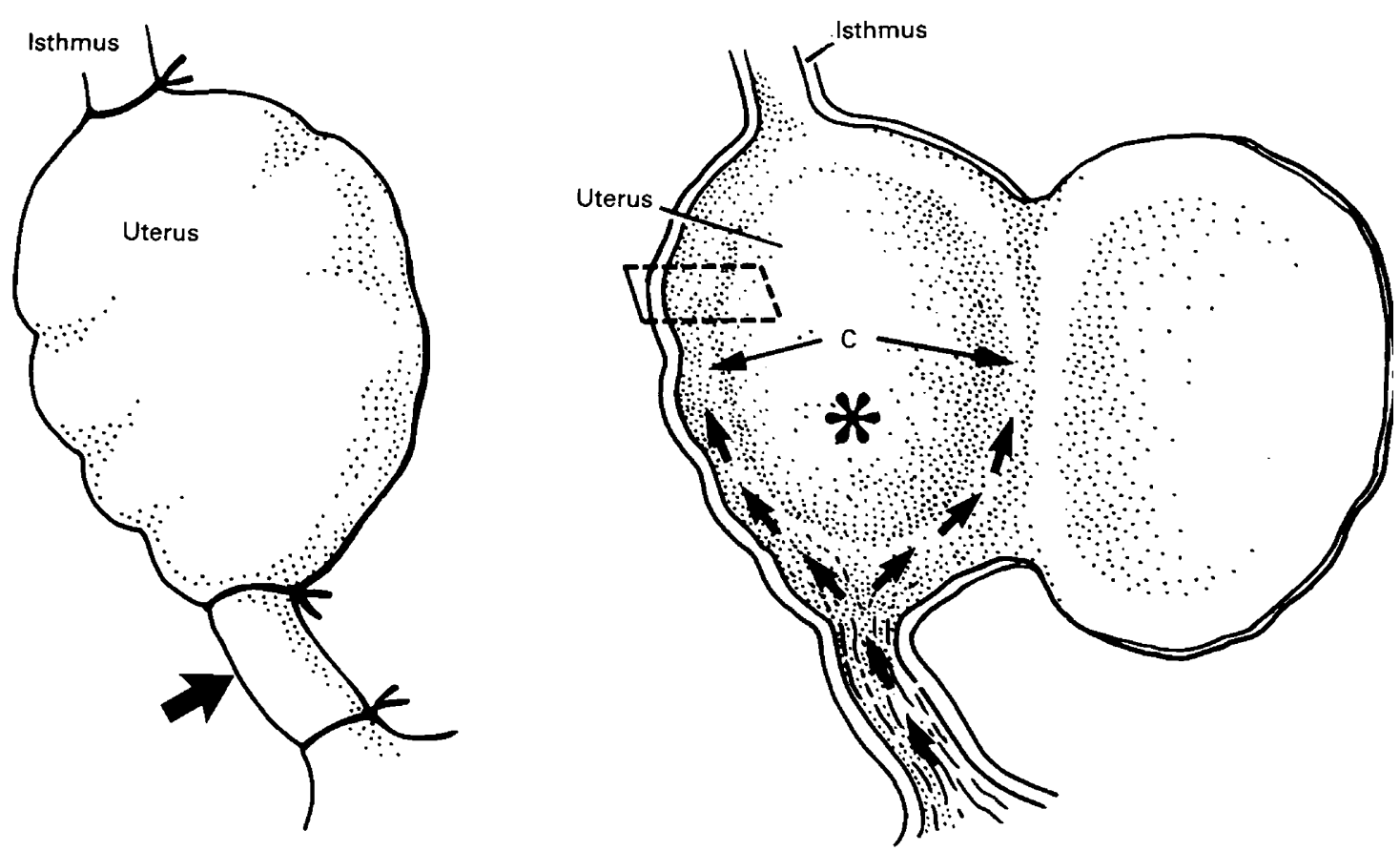

Fig. 2. Uterus and uterine neck (large arrow) of a brown marsupial mouse. Small arrows indicate direction of sperm movement; *slightly convex uterine core; dashed lines represent plane of section and region in Fig. $6 ; \times 6.5$. C, endouterine channel. 


\section{Statistical analysis}

Data were analysed using a standard two-tailed $t$ test.

\section{Results}

\section{Changes in total number of spermatozoa in females after mating}

A total of $37 \times 10^{3} \pm 23 \times 10^{3}$ spermatozoa/side (assuming an equal distribution of spermatozoa in each side of the female tract) were present in the female tract of the Day 1 group after a single mating. No significant difference was observed in the number of spermatozoa occupying the female tract after a single mating in the Day 1, 3 and 7 groups (Fig. 3). In samples taken on Days 10 and 14 after mating, 2 of the 3 animals in each of these groups had ovulated. No spermatozoa were recovered from the reproductive tracts of these animals, but the remaining 2 animals which had not ovulated had $\sim 7 \times 10^{3}$ and $9 \times 10^{3}$ spermatozoa/side, respectively (Fig. 3). In the Day-18 group, 1 female had ovulated, 1 had died prematurely (Day 5) and no intact spermatozoa were recovered from the tract of the third (Fig. 3).

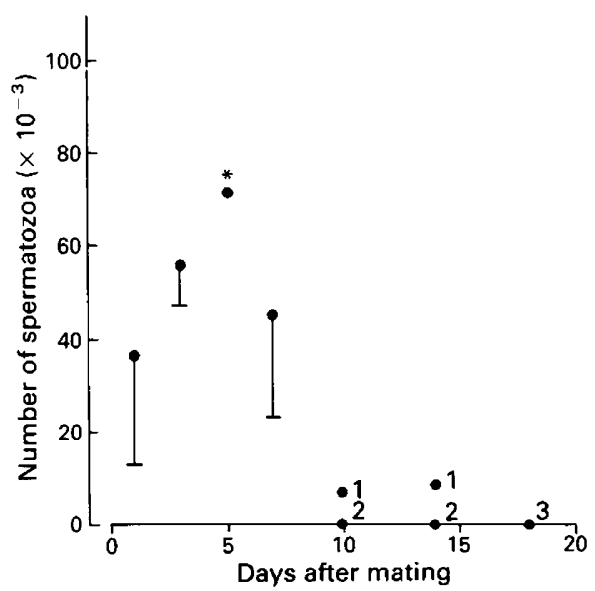

Fig. 3. Changes in the total number of spermatozoa in the female reproductive tract of brown marsupial mice at $1,3,5,7,10,14$ and 18 days after mating. Values are means \pm s.d. for 3 females/group except as indicated. *premature death.

The largest number of spermatozoa in a female tract after a single mating was $72 \times 10^{3}$ spermatozoa/side, from the Day-5 animal (Fig. 3), and the minimum was $\sim 2 \times 10^{3}$ spermatozoa/side on Day 2 after mating. Only $10 \times 10^{3} \pm 7 \times 10^{3}$ spermatozoa/side were found in Day 2 females, significantly less $(P<0.01)$ than the numbers observed on Days 1, 3, 5 and 7 after mating (Fig. 3). All males used in matings with Day 2 females had mated 2 days in succession (hence data from Day-2 animals have not been included in Figs 3 and 4) suggesting that frequency of mating may influence the numbers of spermatozoa delivered at ejaculation.

\section{Sperm distribution in the female tract}

Throughout the period of study few, if any, spermatozoa were found in the lateral vaginae and no spermatozoa were present in this region from Day 7 after mating (Fig. 4). Between Days 1 and 7 
most of the spermatozoa were in the uterus and isthmus region 1 (Fig. 4). On Day 1 after mating, $60 \%$ of the spermatozoa in the female tract $\left(23 \times 10^{3} \pm 13 \times 10^{3}\right.$ spermatozoa/side) were found in isthmus 1 , and most of the remaining spermatozoa $\left(13 \times 10^{3} \pm 11 \times 10^{3}\right.$ spermatozoa/side; $\sim 35 \%$ ) were present in the uterus (Fig. 4). Histological observations of the isthmus 1 region at this time showed large numbers of spermatozoa in the lumen of the duct and in the sperm storage crypts in this region (Figs 5 and 6).

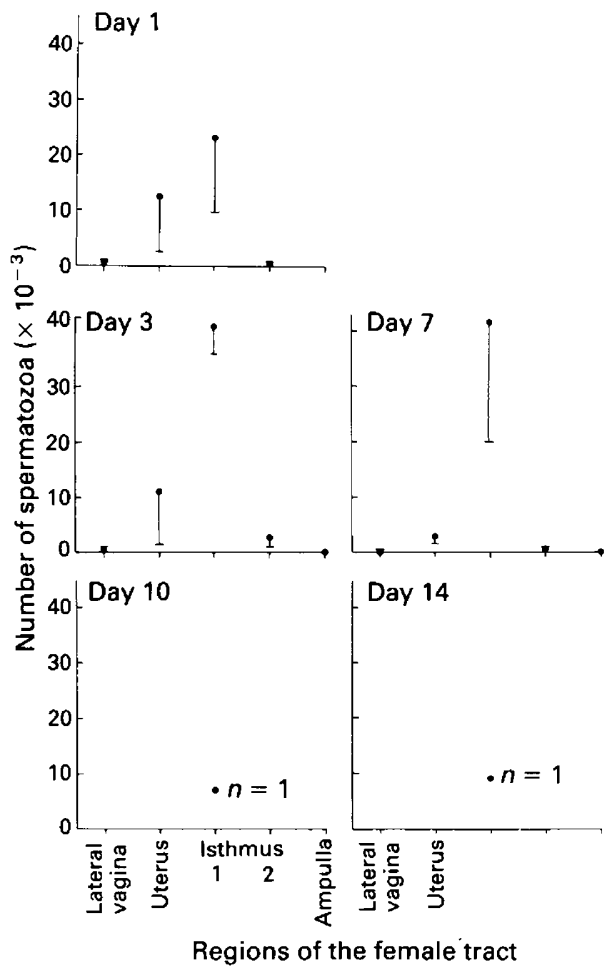

Fig. 4. Changes in sperm distribution in female brown marsupial mice on Days 1, 3, 7, 10 and 14 after mating. Values are means \pm s.d. for 3 females/group except as indicated.

On Day 3 after mating, $72 \%$ of the spermatozoa in the tract $\left(41 \times 10^{3} \pm 5 \times 10^{3}\right.$ spermatozoa/ side) were located in isthmus 1 , with approximately equal proportions in the luminal and crypt areas. About $20 \%\left(11 \times 10^{3} \pm 11 \times 10^{3}\right.$ spermatozoa/side $)$ of the spermatozoa were found in the uterus (Fig. 4). By Day 7 after mating, $91 \%$ of the sperm population $\left(42 \times 10^{3} \pm 23 \times 10^{3}\right.$ spermatozoa/side) was in the isthmus 1 region, most of these being confined to the sperm storage crypts (Fig. 4). Only $6.5 \%$ of the total spermatozoa in the tract at this time $\left(3 \times 10^{3} \pm 1 \times 10^{3}\right.$ spermatozoa/side) were found in the uterus (Fig. 4).

All spermatozoa found in the female tract after Day 7 were restricted to the isthmus 1 region (Fig. 4). Numbers of spermatozoa in the isthmus 2 region (maximum Day 3, $2 \times 10^{3} \pm 1 \times 10^{3}$ ) remained low throughout the study and no spermatozoa were observed in the ampulla even in animals that had recently ovulated, although fertilization had occurred (Fig. 4).

\section{Structure of the uterus and isthmus and sperm-crypt cell associations}

The uterus in A. stuartii is an oval, muscular organ (Fig. 1), which is highly vascularized and appears bright pink when observed fresh. It is connected by a small duct $\sim 4 \mathrm{~mm}$ long, the uterine 


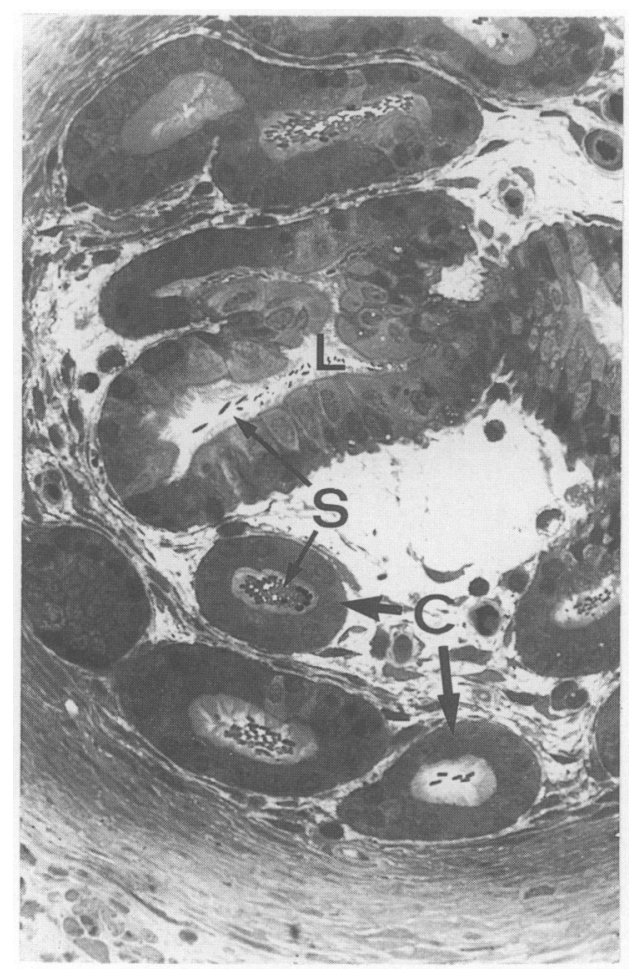

Fig. 5. Cross-section through the isthmus 1 region of the female tract of a brown marsupial mouse, showing lumen $(\mathrm{L})$ and crypts $(\mathrm{C})$ containing spermatozoa $(\mathrm{S}) ; \times 68$.

neck, to the cervix, which opens into the anterior expansion of the lateral vagina. Longitudinal bisection of the uterine neck revealed a series of thick ridges of tissue, which run longitudinally toward the body of the uterus (Fig. 2). Bisection of the uterus exposed a channel around its perimeter, which surrounded a central, fleshy, slightly convex core of tissue (Fig. 2). The lumen of the uterus, which was not distended with fluid, appeared $\mathbf{T}$-shaped in transverse section in the vicinity of this channel (Fig. 7). Uterine spermatozoa were almost exclusively restricted to this portion of the uterus.

The oviduct is highly convoluted, $\sim 2 \mathrm{~cm}$ long when uncoiled and narrows progressively toward the fimbria (Fig. 1). Following successful mating, spermatozoa were clearly observed, using a dissecting microscope at low power, through the walls of the isthmus 1 region on both sides in the vicinity of the sperm storage crypts. Here they appear as 'white flashes' against the wall of the duct and seem to accumulate in the areas where the duct bends (Fig. 1). The duct narrows noticeably in the proximal regions of isthmus 2 and again in the ampulla and deposits of spermatozoa were not seen with the dissecting microscope in either of these regions during the study.

Spermatozoa released from the uterus during the distribution studies were very active in culture medium whereas those from the lumen and crypts of isthmus 1 were invariably immotile and showed no reactivation of motility in medium.

Spermatozoa within the isthmic crypts were often seen with their heads close to or entangled in the long microvilli of nonciliated crypt cells, but none was observed embedded into the apical surface of these or ciliated cells (Fig. 8). Ultrastructural features of spermatozoa in luminal and crypt areas of isthmus 1 were similar (Fig. 6a,b) and remained unchanged during the period of sperm storage. No evidence of sperm degeneration was observed in spermatozoa in the isthmus outside the crypts. 
(a)

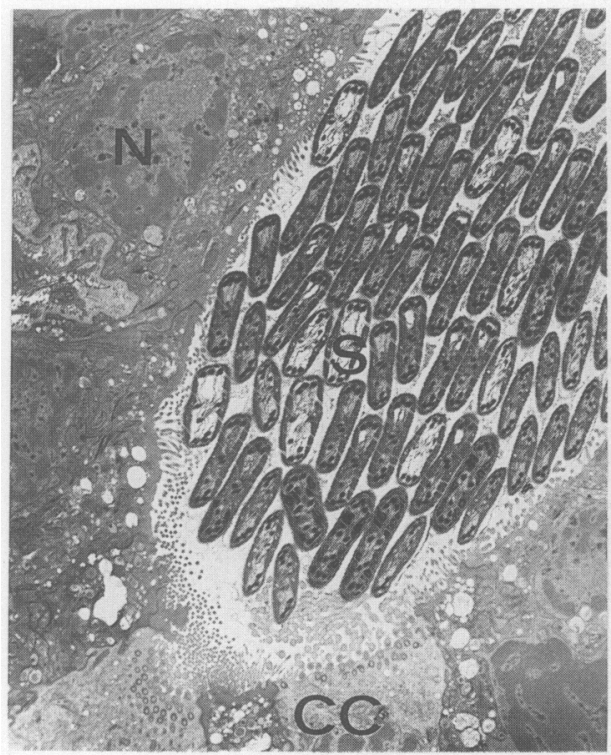

(b)

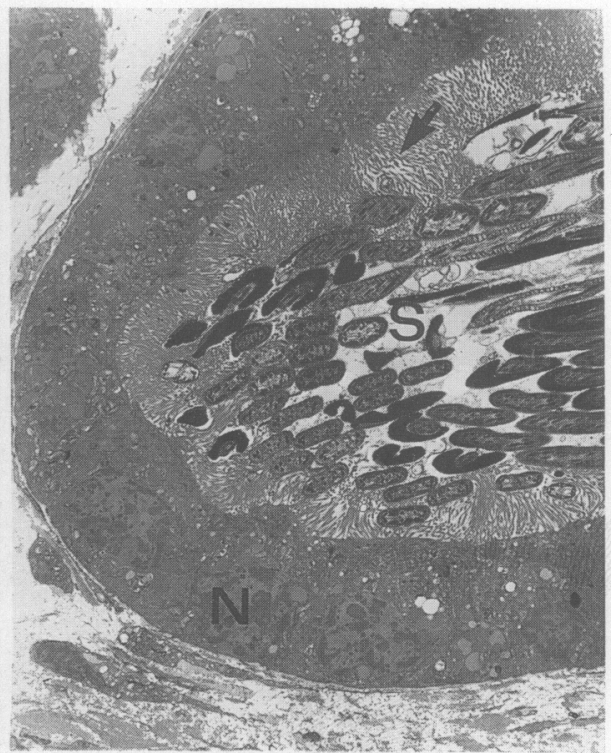

Fig. 6. Transverse section through the isthmus 1 region of the female reproductive tract of a brown marsupial mouse (a) luminal portion showing, spermatozoa (S), ciliated cell (CC) and nonciliated cell nuclei $(\mathrm{N}) ; \times 2600$; (b) a portion of a crypt showing, spermatozoa (S), nonciliated cell nuclei $(\mathrm{N})$ and microvilli (arrows) $(\mathrm{M}) ; \times 1900$.

No spermatozoa were obtained from the female tract taken 18 days after mating, but histological examination of the contralateral isthmus showed small aggregations of degenerating spermatozoa in the sperm storage crypts. Most of these spermatozoa were in advanced stages of degeneration as indicated by the loss of plasma membranes, nuclear decondensation and the degradation or disarray of structural elements of the tail (Fig. 9).

\section{Discussion}

The numbers of spermatozoa in ejaculates of eutherian mammals (e.g. mouse $50 \times 10^{6}$; rat $58 \times 10^{6}$; rabbit $200-500 \times 10^{6}$ ) and most marsupials (brushtailed possum $129 \times 10^{6}$; koala $74 \times 10^{6}$ ) are very large (Moore \& Bedford, 1978; Amann, 1981; Bedford et al., 1984; Rodger \& Pollitt, 1981; Southwick \& Temple-Smith, 1988; Wildt et al., 1991), but few of these reach the isthmus region of the oviduct before fertilization (e.g. 1 in 5000 to 1 in 10000 in the rabbit) and even fewer pass into the ampulla at the time of fertilization (Overstreet \& Cooper, 1978, 1979).

In dasyurid marsupials, however (Bedford et al., 1984; Taggart \& Temple-Smith, 1989, 1990a), few spermatozoa are present in the epididymis before and during the breeding season. Brown marsupial mice, for example, despite being polygynous, have only $\sim 3.5 \times 10^{6}$ spermatozoa/ epididymis at the start of the mating season with limited possibility for replenishment from the testis due to total spermatogenic failure before the onset of mating (Kerr \& Hedger, 1983). Previously we estimated that between $80 \times 10^{3}$ and $480 \times 10^{3}$ spermatozoa were delivered at ejaculation in this species (Taggart \& Temple-Smith, 1990a). This study has shown that, although the number of spermatozoa inseminated is very low by mammalian standards, sperm transport is extremely efficient in this species and very large numbers of the spermatozoa reach the isthmus before ovulation. Approximately $40 \times 10^{3}$ of the ejaculated spermatozoa reach each isthmus, giving a remarkable success ratio of between 1 in 1 and 1 in 7 , using our previous estimates of sperm 


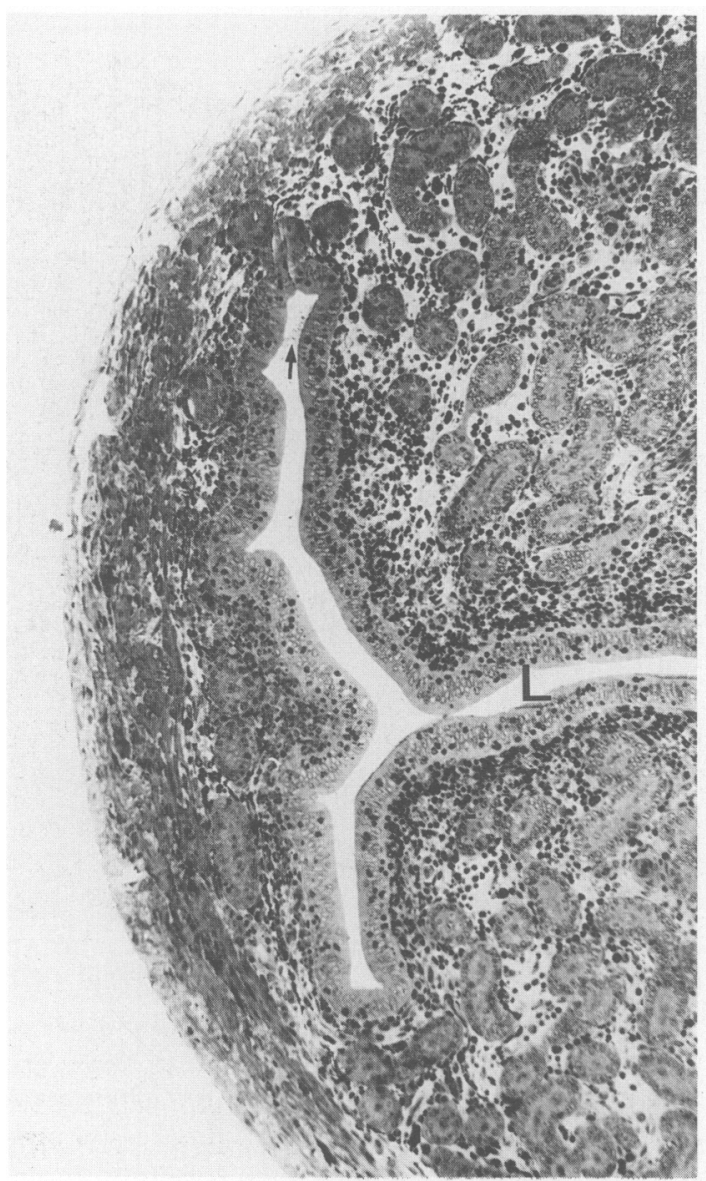

Fig. 7. Transverse section through the channel around the perimeter of the uterus of a brown marsupial mouse, showing its T-shaped appearance, partially occluded uterine lumen (L), spermatozoa (arrow); $\times 32$.

content in the ejaculate. This sperm transport ratio in the brown marsupial mouse is higher than that reported for the Virginian opossum ( 1 in 20, Bedford et al., 1984) and similar to recent estimates for another dasyurid species, the fat-tailed dunnart, Sminthopsis crassicaudata ( 1 in 10, Breed et al., 1989), which also has low numbers of epididymal and ejaculated spermatozoa.

A marked reduction in the number of spermatozoa found in the reproductive tract of female brown marsupial mice after mating was observed when the males used in these matings had mated 2 days in succession (Day 2 group). It seems likely, therefore, assuming that ejaculated spermatozoa originate from the caudal region of the epididymis as they do in other mammals (Thibault, 1973; Taggart \& Temple-Smith, 1989), that replenishment of caudal epididymal sperm reserves takes more than 1 day in brown marsupial mice and that a single ejaculation is sufficient to deplete most of the stored reserve of spermatozoa in the epididymis of this species. It therefore appears that, during the short breeding season of the multiple mating brown marsupial mouse (Lee et al., 1977), numbers of spermatozoa in an average ejaculate may be very low due to frequent and repeated ejaculation. Therefore the number of spermatozoa ejaculated is probably closer to the minimum outlined by Taggart \& Temple-Smith (1990a) and associated with the time required to replenish the reserves of spermatozoa for ejaculation in the cauda epididymidis. 


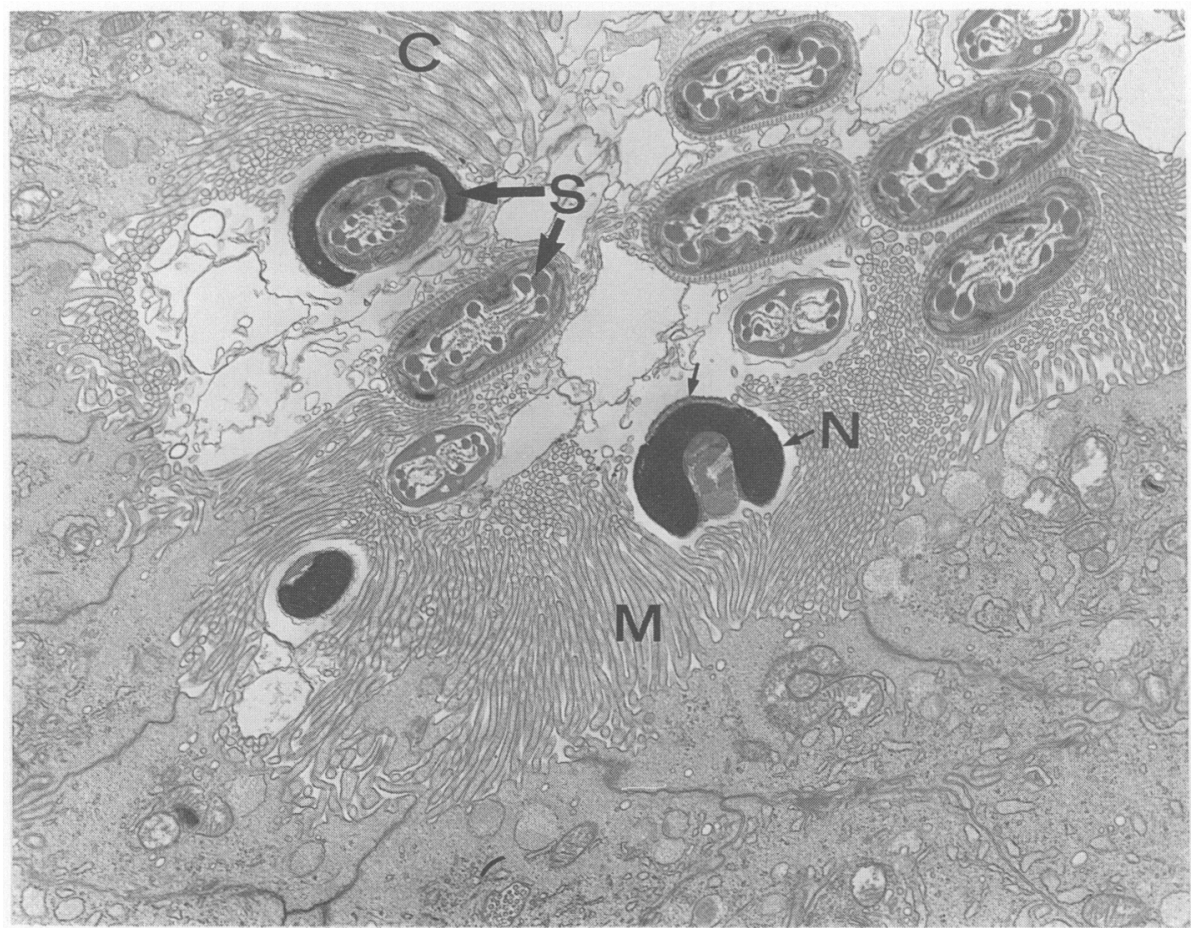

Fig. 8. Section through the luminal region of an isthmic crypt of a brown marsupial mouse, showing relationship between spermatozoa (S), epithelial microvilli (M) and cilia (C) and sperm nucleus $(\mathrm{N})$ and acrosome (small arrow); $\times 10200$.

Several factors may explain the successful transport of Antechinus spermatozoa through the female tract. In addition to the unusual, sinusoidal mode of progressive sperm motility (Taggart \& Temple-Smith, 1990b), which may be a principal factor contributing to the improved efficiency of sperm transport in this and perhaps other dasyurids, the structural features of the female tract, for example, the longitudinal ridging in the uterine neck and the channel around the perimeter of the uterus into which uterine spermatozoa are almost exclusively restricted, may also enhance the efficiency of sperm transport by a directing effect on sperm movement. Sperm storage for extended periods in the female is another factor influencing the success of these low numbers of ejaculated spermatozoa.

In most mammals, spermatozoa in the female tract survive for short periods, often only hours, and fertilization usually occurs within 1 day after mating (Bishop, 1970). Long-term storage of spermatozoa occurs in the uterus and oviducts of a number of vertebrates (Metten, 1939; Fox, 1963; Bobr et al., 1964; Thibault, 1973), but is uncommon in mammals. In insectivorous bats (Hartman, 1933; Racey \& Potts, 1970; Racey, 1979; Krutzsch et al., 1982; Racey et al., 1987; Rasweiler, 1987) spermatozoa are often stored for extended periods (several months) in association with torpor and/or hibernation (Racey, 1979). In all vertebrates in which appropriate investigations have been conducted, close spatial relationships have been observed between the stored spermatozoa and the epithelium lining these storage sites (Pearson, 1944; Yanagimachi \& Chang, 1963; Racey \& Potts, 1970), but no relationship has been established between the type of contact with epithelial cells and duration of sperm survival (Thibault, 1973).

In marsupials, extended periods of sperm storage in the female tract have been reported in 3 families. In didelphids (Rodger \& Bedford, 1982) and dasyurids (Hill \& O’Donoghue, 1913; Woolley, 1966; Godfrey, 1969, 1975; Selwood, 1980; Breed et al., 1989) storage occurs in specialized crypts in the isthmus of the oviduct close to the utero-tubule junction whereas in 


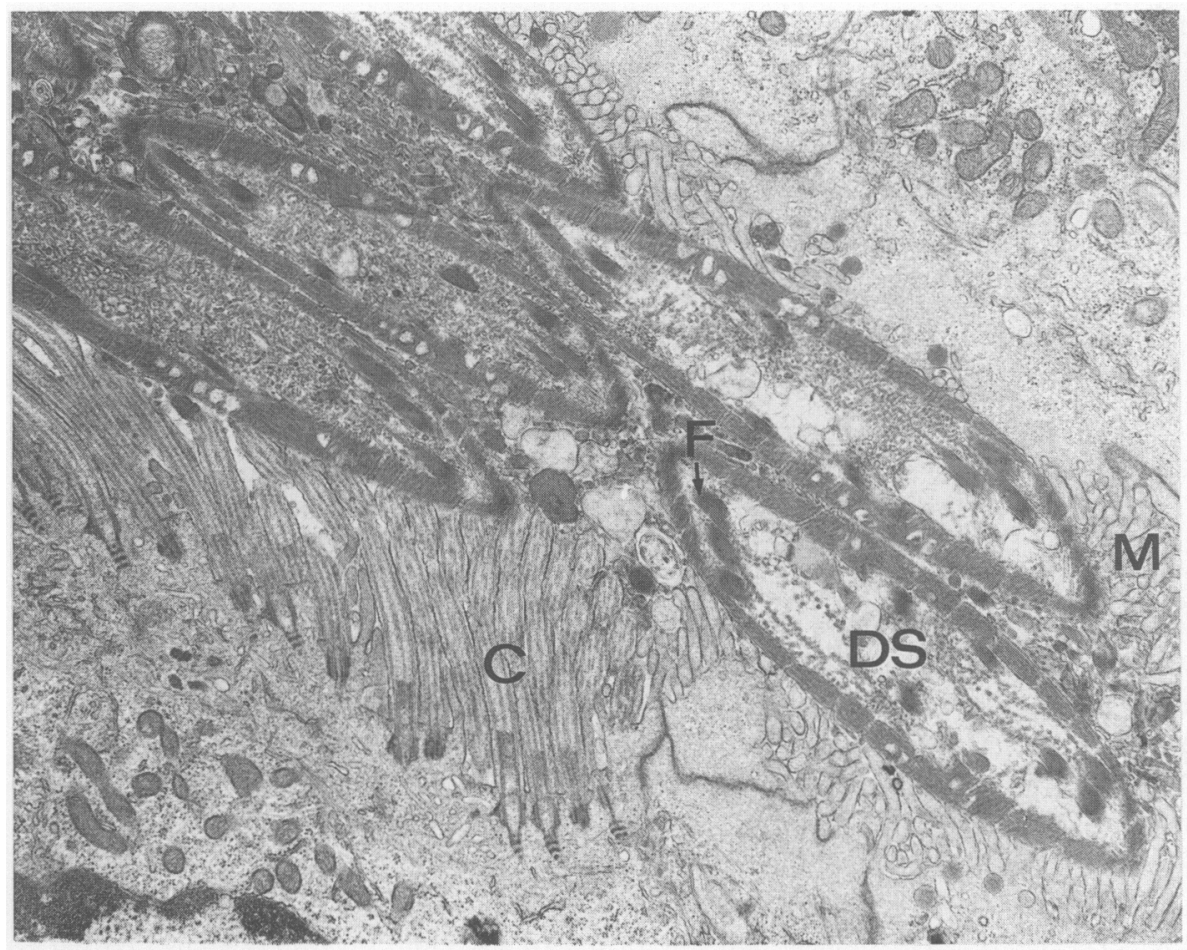

Fig. 9. Section through the luminal region of an isthmic crypt of a brown marsupial mouse at Day 18 after mating, showing aggregations of degenerating spermatozoa (DS), dense fibres (F), microvilli (M) and cilia (C); $\times 19300$.

bandicoots (Lyne \& Hollis, 1977) spermatozoa are stored in vaginal caeca or seminal receptacles. Viable sperm storage in brown marsupial mice occurs for up to 2 weeks before ovulation (Selwood, 1982, 1987) and, as observed in the fat-tailed dunnart (Breed et al., 1989), most of these spermatozoa are restricted to the crypts, often with their heads in close proximity to the microvilli of the epithelial cells. Unlike bats, however (Racey \& Potts, 1970), no special orientation of spermatozoa in relation to the crypt cells was observed in brown marsupial mice or the fat-tailed dunnart and the close relationship of the sperm head to the epithelial microvilli may simply be related to the dynamics of sperm movement into the crypts. Epithelial cells in the crypts of brown marsupial mice did not appear to perform any special protective function for the spermatozoa and all isthmic spermatozoa, whether in the lumen or crypt areas of isthmus 1, appeared normal with no signs of degeneration for at least 14 days after insemination.

Observations on the motility of spermatozoa in female brown marsupial mice indicated that spermatozoa which had reached the sperm storage region in isthmus 1 were immotile. Motility was greatest in spermatozoa removed from the uterine segments. These findings are in agreement with observations of sperm transport in other mammals (Zamboni, 1972; Yanagimachi \& Mahi, 1976; Overstreet \& Cooper, 1978; Shalgi \& Kraicer, 1978; Hunter \& Nichol, 1983). Spermatozoa remained in the lower isthmus of these species for several hours before ovulation and were transported to the ampulla at the time of ovulation. Hunter \& Nichol (1983) have suggested that restriction of spermatozoa to the lower isthmus during the preovulatory period may avoid polyspermy, isolate spermatozoa from the metabolic stimulation of uterine and ampullary fluids, protect spermatozoa from phagocytosis and/or conserve energy. Oviducal sperm storage may have similar functions in $A$. stuartii as well as the important synchronization of male and female reproductive effort. 
The effect on fertility of prolonged sperm storage in the female tract is crucial to the breeding success of species using this system. Reduced fertility was observed by Selwood \& McCallum (1987) in brown marsupial mice up to 5 days after mating. They suggested that this resulted from (i) low numbers of spermatozoa in the oviduct and (ii) developmental failure, possibly caused by an insufficient period of exposure of spermatozoa to the female tract, resulting in incomplete sperm maturity. Data from this study, however, show that numbers of spermatozoa in the isthmus are high between Days 1 and 7 after mating suggesting that low fertility during this period (Selwood \& McCallum, 1987) is probably due to a requirement for several days' exposure to the female tract before maturation is complete.

Fertility in brown marsupial mice was greatest 6-13 days after mating (Selwood \& McCallum, 1987). The percentage of normal embryos increased until a mean of 9.5 days after mating and decreased thereafter (Selwood \& McCallum, 1987). These data fit with results from the present study in which high numbers of crypt-stored spermatozoa were maintained up to Day 7 after mating $\left(42 \times 10^{3} \pm 22 \times 10^{3}\right.$ spermatozoa/side) and were declining at Days 10 and 14 after mating. Hence, the period when the percentage of normal embryos in $A$. stuartii is greatest correlates well with the time when large numbers of crypt-stored spermatozoa occur in the isthmus.

Selwood \& McCallum (1987) suggested that a large decrease in fertility in A. stuartii after Day 13 of crypt storage was caused by declining numbers of spermatozoa in the oviducal crypts. This was supported by several observations. For example, few spermatozoa were observed trapped within the investments of eggs fertilized around this time, virtually no spermatozoa were trapped within the investments of unfertilized eggs during this period and qualitative observations showed a very low sperm density in the oviduct of 2 females killed at Day 14 after mating. Counts of spermatozoa in the isthmus in our study support this assumption. Sperm loss in A. stuartii probably results from degeneration of crypt spermatozoa as observed on Day 18 after mating, perhaps due to phagocytosis of spermatozoa by crypt cells, as described by Breed et al. (1989) or to increased numbers of leucocytes as observed in bats (Krutzsch et al., 1982). No histological evidence was found during this study to support either hypothesis.

Our studies showed that sperm transport in female brown marsupial mice is extremely efficient and that a special relationship exists between spermatozoa and the oviducal environment, which results in viable sperm storage. Detailed investigations are now required to determine the specific characteristics and mode of regulation of the luminal environment of the oviduct during sperm storage and after sperm release. This knowledge may have some implications in developing alternative methods for storage and preservation of mammalian spermatozoa.

We thank J. Hoy for excellent technical assistance, J. McKervey and B. Lloyd for photographic assistance; S. Simpson for help with preparation of diagrams and the Victorian Department of Conservation, Forests and Lands for approval to conduct this investigation.

\section{References}

Amann, R.P. (1981) A critical review of methods for evaluation of spermatogenesis from seminal characteristics. J. Androl. 2, 37-58.

Amann, R.P., Johnson, L., Thompson, D.L. \& Pickett, B.W. (1976) Daily spermatozoal production, epididymal spermatozoal reserves and transit time of spermatozoa through the epididymis of the rhesus monkey. Biol. Reprod. 15, 586-592.

Bedford, J.M., Rodger, J.C. \& Breed, W.G. (1984) Why so many mammalian spermatozoa-a clue from marsupials? Proc. R. Soc. Lond. B. 221, 221-233.

Bishop, M.W.H. (1970) Ageing and reproduction in the male. J. Reprod. Fert., Suppl. 12, 65-88.
Bobr, L.W., Lorenz, F.W. \& Ogasawara, F.X. (1964) Distribution of spermatozoa in the oviduct and fertility in domestic birds. J. Reprod. Fert. 8, 39- 47 .

Bradley, A.J., McDonald, I.R. \& Lee, A.K. (1980) Stress and mortality in a small marsupial (Antechinus stuartii MacLeay). Gen. comp. Endocrinol. 40, 188-200.

Breed, W.G., Leigh, C.M. \& Bennett, J.H. (1989) Sperm morphology and storage in the female reproductive tract of the fat-tailed dunnart, Sminthopsis crassicaudata (Marsupialia: Dasyuridae). Gamete Res. 23, 61-75. 
Cummins, J.M. (1981) Sperm maturation in the possum Trichosurus vulpecula. A model for comparison with eutherian mammals. In Marsupials in New Zealand, pp. 23-39, Ed. B.D. Bell. Victoria University, Wellington.

Fox, W. (1963) Special tubules for sperm storage in female lizards. Nature, Lond. 198, 500-501.

Godfrey, G.K (1969) Influence of increased photoperiod on reproduction in the dasyurid marsupial, Sminthopsis crassicaudata. J. Mammal. 50, 132-133.

Godfrey, G.K. (1975) A study of oestrus and fecundity in a laboratory colony of mouse opossums (Marmosa robinsoni). J. Zool., Lond. 175, 541-555.

Hartman, C.G. (1933) On survival of spermatozoa in the female genital tract of the bat. $Q$. Rev. Biol. 8, $185-193$.

Hill, J.P. \& O'Donoghue, C.H. (1913) The reproductive cycle in the marsupial Dasyurus viverrinus. $Q . J$. microsc. Sci. 59, 133-174.

Hunter, R.H.F. \& Nichol, R. (1983) Transport of spermatozoa in the sheep oviduct: Preovulatory sequestering of cells in the caudal isthmus. $J$. exp. Zool. 228, $121-128$

Kerr, J.B. \& Hedger, M.P. (1983) Spontaneous spermatogenic failure in the marsupial mouse Antechinus stuartii MacLeay (Dasyuridae: Marsupialia). Aust. $J$. Zool. 31, 445-466.

Krutzsch, P.H., Crichton, E.G. \& Nagle, R.B. (1982) Studies on prolonged spermatozoa survival in Chiroptera: a morphological examination of storage and clearance of intrauterine and caudal epididymal spermatozoa in the bats Myotis lucifugus and $M$. velifer. Am. J. Anat. 165, 421-434.

Lee, A.K. \& Cockburn, A. (1985) Evolutionary Ecology of Marsupials (Monographs on Marsupial Biology). Cambridge University Press, Cambridge.

Lee, A.K., Bradley, A.J. \& Braithwaite, R.W. (1977) Corticosteroid levels and male mortality in Antechinus stuartii. In The Biology of Marsupials, pp. 209220. Eds B. Stonehouse \& D. Gilmore. Macmillan, London.

Lyne, A.G. \& Hollis, D.E. (1977) The early development of marsupials, with special reference to the bandicoots. In Reproduction and Evolution, pp. 293-302. Eds J. H. Calaby \& C. H. Tyndale-Biscoe. Australian Academy Science, Camberra.

Metten, H. (1939) Studies on the reproduction of the dogfish. Phil. Trans. R. Soc. Lond. 230, 217-238.

Moore, H.D. \& Bedford, J.M. (1978) Fate of spermatozoa in the male. 1. Quantitation of sperm accumulation after vasectomy in the rabbit. Biol. Reprod. 18, 784-790.

Overstreet, J.W. \& Cooper, G.W. (1978) Sperm transport in the reproductive tract of the female rabbit 1 . The rapid transit phase of transport. Biol. Reprod. 19, 101-114.

Overstreet, J.W. \& Cooper, G.W. (1979) Effect of ovulation and sperm motility on the migration of rabbit spermatozoa to the site of fertilization. J. Reprod. Fert. 55, 53-59.

Pearson, O.P. (1944) Reproduction in the shrew (Blarina brevicauda Say). Am. J. Anat. 75, 39-93.

Racey, P.A. (1979) The prolonged storage and survival of spermatozoa in Chiroptera. J. Reprod. Fert. 56, 391-402.
Racey, P.A. \& Potts, D.M. (1970) Relationship between stored spermatozoa and the uterine epithelium in the pipestrelle bat (Pipistrellus pipistrellus). J. Reprod. Fert. 22, 57-63.

Racey, P.A., Uchida, T.A., Mori, T., Avery, M.I. \& Fenton, M.B. (1987) Sperm - epithelium relationships in relation to the time of insemination in little brown bats (Myotis lucifugus). J. Reprod. Fert. 80, 445-454.

Rasweiler, J.J. (1987) Prolonged receptivity to the male and the fate of spermatozoa in the female black mastiff bat, Molossus ater. J. Reprod. Fert. 70, 643-654.

Rodger, J.C. \& Bedford, J.M. (1982) Induction of oestrus, recovery of gametes, and the timing of fertilization events in the opossum, Didelphis virginiana. $J$. Reprod. Fert. 64, 159-169.

Rodger, J.C. \& Pollitt, C.C. (1981) Radiographic examination of electroejaculation in marsupials. Biol. Reprod. 24, 1125-1134.

Selwood, L. (1980) A timetable of embryonic development of the dasyurid marsupial Antechinus stuartii (MacLeay). Aust. J. Zool. 28, 649-688.

Selwood, L. (1982) A review of maturation and fertilization in marsupials with special reference to the dasyurid: Antechinus stuartii. In Carnivorous Marsupials, vol. I, pp. 65-76. Ed. M. Archer. Royal Zoological Society, NSW, Sydney.

Selwood, L. (1983) Factors influencing pre-natal fertility in the brown marsupial mouse, Antechinus stuartii. $J$. Reprod. Fert. 68, 317-324.

Selwood, L. (1985) Synchronisation of oestrus, ovulation and birth in female Antechinus stuartii (Marsupialia: Dasyuridae). Aust. J. Mammal. 8, 91-96.

Selwood, L. (1987) Embryonic development in culture of two dasyurid marsupials, Sminthopsis crassicaudata (Gould) and Sminthopsis macroura (Spenser) during cleavage and blastocyst formation. Gamete Res. 16, 355-370.

Selwood, L. \& McCallum, F. (1987) Relationship between longevity of spermatozoa after insemination and the percentage of normal embryos in brown marsupial mice (Antechinus stuartii). J. Reprod. Fert. 79, 495-503.

Shalgi, R. \& Kraicer, P.F. (1978) Timing of sperm transport, sperm penetration and cleavage in the rat. $J$. exp. Zool. 204, 353-360.

Southwick, G.J. \& Temple-Smith, P.D. (1988) Epididymal microsurgery: current techniques and new horizons. Microsurgery 9, 266-277.

Taggart, D.A. \& Temple-Smith, P.D. (1989) Structural features of the epididymis in a dasyurid marsupial (Antechinus stuartii). Cell Tissue Res. 258, 203-210.

Taggart, D.A. \& Temple-Smith, P.D. (1990a) The effects of breeding season and mating on total number and relative distribution of spermatozoa in the epididymis of the brown marsupial mouse, Antechinus stuartii. $J$. Reprod. Fert. 88, 81-91.

Taggart, D.A. \& Temple-Smith, P.D. (1990b) An unusual mode of progressive motility in spermatozoa from the dasyurid marsupial, Antechinus stuartii. Reprod. Fert. Dev. 2, 107-114.

Temple-Smith, P.D. \& Bedford, J.M. (1976) The features of sperm maturation in the epididymis of a marsupial, the brush tailed possum Trichosurus vulpecula. Am.J. Anat. 147, 471-500. 
Thibault, C. (1973) Sperm transport and storage in vertebrates. J. Reprod. Fert., Suppl. 18, 39-53.

Wildt, D.E., Bush, M., O'Brien, S.J.O., Murray, N.D., Taylor, A. \& Marshall Graves, J.A. (1991) Semen characteristics in free-living koalas (Phascolarctos cinerus). J. Reprod. Fert. 92, 99-107.

Woolley, P.A. (1966) Reproduction in Antechinus spp. and other dasyurid marsupials. Symp. zool. Soc. Lond. 15, 281-294.

Yanagimachi, R. \& Chang, M.C. (1963) Sperm ascent through the oviduct of the hamster and the rabbit in relation to the time of ovulation. J. Reprad. Fert. 6, 413-420.

Yanagimachi, R. \& Mahi, C.A. (1976) The sperm acrosome reaction and fertilization in the guinea-pig: a study in vivo. J. Reprod. Fert. 46, 49-54.

Zamboni, L. (1972) Fertilization in the mouse. In Biology of Mammalian Fertilization and Implantation, pp. 213-262. Eds K.S. Moghissi \& E.S. Hafez. Charles C. Thomas, Springfield.

Received 6 August 1990 